\title{
DESPACHOS NO MUSEU sabe-se lá o que vai acontecer...
}

SuELY RoLNIK

Psicanalista, Coordenadora do Núcleo de Estudos da Subjetividade da Pós-Graduação em Psicologia Clínica da PUC-SP

\begin{abstract}
Resumo: A vida em suas diferentes fórmulas de criação constitui um dos alvos privilegiados do investimento do capitalismo contemporâneo. Para fabricar e comercializar clones, o capitalismo extrai as matrizes não só da biodiversidade na natureza, mas também do multiculturalismo de modalidades de produção de sentido, de territórios de existência e de subjetividade. Um dos maiores desafios do artista contemporâneo está em se instalar no próprio âmago dessa ambigüidade, associando-se ao investimento capitalista, mas negociando para manter a vida como princípio ético organizador, tolhendo assim seu vetor perverso.

Palavras-chave: cultura e capitalismo; arte e resistência; instauração.
\end{abstract}

Trata-se sempre de liberar a vida lá onde ela é prisioneira, ou de tentar fazê-lo num combate incerto.

Gilles Deleuze e Félix Guattari (1992:222)

A vida, em sua potência de variação, constitui um dos alvos privilegiados do investimento do capitalismo contemporâneo. Tendo esgotado os horizontes visíveis para sua expansão, é no invisível que o capital irá descobrir esta sua mina inexplorada: extrair as fórmulas de criação da vida em suas diferentes manifestações será seu alvo e também a causa de sua inelutável ambigüidade. É que se, por um lado, para atingir seu alvo lhe será indispensável investir em pesquisa e invenção, o que aumenta as chances de expansão da vida, por outro, não é a expansão da vida a meta de seu investimento, mas sim a fabricação e a comercialização de clones dos produtos das criações da vida, de modo a ampliar o capital, seu princípio norteador. O exemplo mais óbvio são as pesquisas genéticas que resultam num banco de dados de DNA, que alimenta a indústria biotecnológica com matrizes a serem reproduzidas, até mesmo num futuro remoto. Porém, o capitalismo se interessa em extrair a fórmula não só da vida biológica, mas igualmente da vida subjetiva, na qual se produz o sentimento de si e se configura um território de existência, sem o qual dificilmente se consegue sobreviver. Como a biodiversidade na natureza, fonte exuberante de investimento para o capital, há um multiculturalismo de modalidades de constituição de subjetividade.

Assim, o neocapitalismo convoca e sustenta modos de subjetivação singulares, mas para serem reproduzidos, separados de sua relação com a vida, reificados e transformados em mercadoria: clones fabricados em massa, comercializados como "identidades prêt-à-porter"(Rolnik, 1997). O que se vende são imagens destas identidades/ mercadorias que serão consumidas, inclusive, por aqueles de cuja medula subjetiva o capital se alimentou para produzi-las. Na reinvenção contemporânea do capitalismo, a distância entre produção e consumo desaparece: o próprio consumidor torna-se a matéria-prima e o produto de sua maquinação.

Clones de subjetividade constituem padrões de identificação efêmeros. Para fazer girar esse mercado, é necessário que novos tipos de clone sejam produzidos o tempo todo, enquanto outros saem de linha, tornam-se obsoletos. A diferença entre anomalia e anormalidade pode ser útil para avançar nesta reflexão. "Anomalia" é uma palavra de origem grega, que designa o rugoso, o desigual, o singular, enquanto "anormalidade", uma palavra de origem latina, qualifica aquele que contradiz a regra, definindo-se em relação a características genéricas. ${ }^{1}$ Assim, na tradição latina, as manifestações do que é o mais próprio da vida, sua potência criadora, são interpretadas como negação e, conseqüentemente, condenáveis. Aparentemen- 
te, no modo de produção atual, esta tradição estaria se deslocando: as manifestações da potência criadora tendem a não mais ser interpretadas como anormalidade, transgressão de uma referência absolutizada, mas sim como anomalia; tomadas em sua positividade, tais manifestações deixam de ser malditas. Pelo contrário, a anomalia é acolhida exatamente por sua singularidade, ganhando não só lugar garantido, como também incentivo e prestígio. No entanto, a meta desse forte investimento na anomalia é sua conversão em matéria-prima na fabricação de novos clones, novas formas genéricas de viver, novos tipos de referência homogeneizadora. É, portanto, a tradição latina que insiste, numa versão atualizada.

Em outras palavras, o estatuto da potência criadora hoje é intrinsecamente marcado por uma ambigüidade: a criação nunca foi tão festejada, mas desde que o princípio de sua produção deixe de ser prioritariamente a vida (a problematização do que impede sua expansão e a invenção de territórios que a viabilizem) para se submeter ao capital como princípio organizador central. Caso contrário, por não haver outras vias de reconhecimento social a não ser por semelhança e analogia em relação aos padrões mesmo que efêmeros, a anomalia corre o risco de cair numa espécie de limbo, sem qualquer presença efetiva na cena social e, portanto, sem qualquer poder de interferência nas transformações deste cenário. Assim, as subjetividades nesse regime têm duas opções: serem criadoras, mas para se converter em matéria-prima de identidades prêt-àporter, ou serem suas passivas consumidoras. Fora disso, as invenções da vida tendem a não ter qualquer sentido ou valor.

Exploração invisível de um bem invisível, a vida, é igualmente no invisível que deverão operar as artimanhas para combatê-la. A resistência, hoje, tende a não mais se situar por oposição à realidade vigente, numa suposta realidade paralela; seu alvo agora é o princípio que norteia o destino da criação, já que, como visto, esta tornou-se uma das principais - senão a principal - matérias-primas do modo de produção atual. O desafio está em enfrentar a ambigüidade dessa estratégia contemporânea do capitalismo, colocar-se em seu próprio âmago, associando-se ao investimento do capitalismo na potência criadora, mas negociando para manter a vida como princípio ético organizador. Este é um desafio que se coloca atualmente em todos os meios, com problemas específicos em cada um deles.

A arte é um meio no qual tal estratégia incide com especial vigor, pois constitui um manancial privilegiado de potência criadora, ativa na subjetividade do artista e materializada em sua obra. Artistas são por princípio anômalos: subjetividades vulneráveis aos movimentos da vida, cuja obra é a cartografia singular dos estados sensíveis que sua deambulação pelo mundo mobiliza. É a anomalia dos artistas e de suas criações que faz girar o mercado da arte. Porém, se, por um lado, isto intensifica as oportunidades de criação e circulação no mercado, por outro, a obra, para entrar no circuito, tende a ser clonada, esvaziada do problema vital que ela cartografou. Igualmente clonada tende a ser a subjetividade do artista, esvaziada de sua singularidade em processo e transformada em identidade, de preferência glamurizada. Juntas, obra e subjetividade traficadas, formam o pacote a ser veiculado pela mídia e vendido no mercado da arte, cujo valor será determinado por seu poder de sedução. Se atingir um valor alto, poderá ser ainda vendido em outros mercados - como é o caso da moda - para agregar valor de glamour cultural à marca que o comprar. Ao artista não clonado restam, em geral, poucas saídas para fazer circular sua obra. O destino de muitos é trabalhar nos departamentos de criação das agências que produzem as identidades prêt-àporter: design, publicidade, etc. É no meio da arte que este capitalismo renovado irá encontrar os artífices de suas clonagens.

Em função dessa política específica de separação entre arte e vida, própria do contemporâneo, a utopia de religá-las continua na ordem do dia; mas esta questão, que atravessa toda a história da arte moderna, recoloca-se hoje em novos termos. É exatamente neste ponto que encontramos Tunga e suas "instaurações", ${ }^{2}$ que compreendem um dispositivo singular que, com sagacidade e humor, se instala no âmago da ambigüidade do capitalismo contemporâneo e, de dentro dele, o artista problematiza e negocia com sua nova modalidade de relação com a cultura. Esta estratégia mantém viva a função político-poética da arte e impede que o vetor perverso do capitalismo tome conta da cena, reduzindo a arte à mera fonte de mais-valia e esvaziando-a por completo de sua função.

Embora o nome "instauração" seja uma invenção recente do artista, a proposta que a designa encontra-se em sua obra desde os primórdios. ${ }^{3}$ É a possibilidade de nomeála que surge certamente depois de um determinado ponto de sua trajetória, em que o procedimento se refina e se radicaliza, ganhando uma explicitação maior. ${ }^{4}$ É quando passam a acontecer mais sistematicamente as séries de instaurações em que os objetos, materiais, questões, personagens e elementos com os quais a obra se cria não ape- 
nas são extraídos do próprio meio onde a instauração se faz, mas, o que é mais significativo, muitas vezes são componentes do modo de fazer território no meio em questão. Além disso, os universos escolhidos são não apenas os mais distantes do universo da arte, mas principalmente aqueles em que o vetor perverso do modo de produção dominante atinge seus extremos.

Numa ponta, office boys, figurantes classe $\mathrm{D}$, desempregados, sem-teto, sem-terra, ex-presidiários e, mais recentemente, meninos que já viveram na rua, ${ }^{5}$ ou seja, as sobras do sistema, aqueles que, não podendo ser nem matriz de clone, nem seu consumidor, não chegam sequer a entrar no circuito e ficam vagando pelo limbo. Na outra ponta, top-models, as mais radicalmente reduzidas a suporte de identidade prêt-à-porter, adolescentes cujo maior desejo é prestar-se à clonagem, assim como consumir os clones de si mesmas, a tal ponto que, quando acaba a adolescência e são expelidas deste mercado, é comum sua subjetividade esvaziada cair em depressão.

Assim, os protagonistas que Tunga elege para suas instaurações são aqueles que ficam fora do campo de visibilidade e aqueles que, ao contrário, ocupam toda a extensão do campo e que são eles mesmos pura imagem: os totalmente excluídos e os totalmente incluídos - duas formas de empobrecimento da vida enquanto potência criadora. Miséria material e social de uns; miséria espiritual e subjetiva de outros. O que acontece quando estas figuras tornam-se personagens de si mesmos no cenário da arte? Examinemos algumas instaurações de Tunga.

Convidado pelo Instituto Itaú Cultural para propor uma obra na avenida Paulista, Tunga decide trabalhar com office boys, numa instauração que ele chamará de Cem Terra. Office boys transitam pela avenida durante todo o horário do expediente, pois são eles os mensageiros não-eletrônicos entre os escritórios de luxo das corporações que substituíram as mansões dos barões do café e a elegante avenida e outras áreas da cidade. No entanto, é como se não pertencessem à paisagem oficial, que se interpõe entre o olho e a realidade, como um filtro que impede de enxergálos e os transforma em "sem-terra". Quando Tunga leva uma centena deles a ocupar um quarteirão inteiro da avenida, o que se instaura ali é uma terra que eles criam a seu modo, com a cultura de seus gestos, suas marmitas, as redes onde descansam seus corpos nordestinos, sua facilidade em montar barraca em qualquer lugar a qualquer hora, habituados que estão a nomadizar pela cidade. É a instauração deste mundo que se fará aqui obra de arte. O nada daquelas vidas supostamente inexistentes reanima-se, sai do limbo e volta a pulsar. Anarquiza-se a cartografia da avenida: instalados ali inteiramente à vontade, eles ganham uma existência na paisagem, agora não mais passível de ser ignorada: o espectador/transeunte é obrigado a vê-los, e a relação entre eles não pode mais ser denegada. A força do resultado formal, tanto na escolha dos objetos e corpos quanto em sua disposição na avenida, é inseparável do sucesso da problematização que a obra opera, seu efeito disruptivo.

Já em Tereza, Tunga trabalhará com um grupo de semteto. O nome da instauração vem de uma conhecida prática dos presidiários que consiste em usar os cobertores disponíveis para fazer tranças de vários metros com as quais tentam fugir da prisão. Os sem-teto deverão fazer "terezas" que, neste caso, servirão para fugir do museu ou galeria onde a instauração se faz. Como pontua o próprio artista, a obra aqui é, ao mesmo tempo, individual e coletiva; escultura e instrumento de fuga do espaço da arte; instauração de uma ligação entre o espaço do museu e o espaço da rua onde vivem os sem-teto. Mais uma vez, instaura-se uma confusão no mapa dominante, ao qual estes personagens não estavam incorporados, como os office boys Cem Terra.

Em várias vezes que realizou tanto Cem Terra como Tereza, Tunga foi obrigado a utilizar figurantes classe D para fazer os papéis de office boys ou presidiários. A razão alegada foi a exigência de leis trabalhistas que protegem os atores, mas talvez a razão implícita, mais decisiva, tenha sido o pavor provocado pela idéia de os espaços institucionais da arte serem ocupados por esta "corja de marginais". De qualquer modo, a estratégia não perde seu vigor, pois o que são tais figurantes senão desempregados que desempenham papéis de quem não teve oportunidade de aprender coisa alguma, e só cumpre funções inespecíficas tanto no palco como na vida. Eles pertencem à mesma população que office boys, sem-terra e semteto, adultos ou meninos - todos eles figurantes classe D deste mundo em que vivemos. ${ }^{6}$ Continua portanto sendo no mesmo meio que o trabalho instaura um deslocamento crítico.

Em todas estas instaurações, reativa-se a função poético-política da arte, produz-se uma resistência à tentativa de pervertê-la: a obra volta a ser problematizadora do meio onde ela se faz. Na contramão do sistema que ou reconhece modos de fazer território para cloná-los, ou marginaliza os inclonáveis, Tunga cria para estes modos de subjetivação um espaço de visibilidade onde eles atuam ao vivo, protagonistas de si mesmos, com seu próprio elen- 
co de ferramentas e materiais de construção de território. Os clonáveis, como é o caso das top-models, vivem na cena o movimento contrário àquele que os converte em clichês: a instauração parte exatamente de sua imagem clonada, no próprio meio em que é lançada ao mercado, o desfile de moda, mas para tentar liberar a vida que ficou ali aprisionada. Os não-clonáveis, sobras tornadas invisíveis, como office boys, sem-teto, presidiários e figurantes de classe $\mathrm{D}$, saem dos bueiros da marginalidade e ganham a cena. Embaralham-se as cartas, redistribuem-se os sujeitos no campo de visão, desautoriza-se a cartografia oficial estabelecida pelo capital como princípio norteador.

Neste contexto, pode-se problematizar a instauração Salitre + Enxofre + Carvão, que Tunga propôs para a parceria entre A Quietude da Terra II e o Projeto Axé. ${ }^{7} \mathrm{O}$ objetivo era criar um cotidiano de convívio entre um certo tipo de artistas, de diferentes origens, e garotos ex-habitantes das ruas de Salvador que, inseridos no Projeto Axé, tentam libertar-se do confinamento na marginalidade, tendo na arte uma de suas principais armas. A que vem esta curiosa iniciativa? É verdade que entre crianças e artistas há ressonâncias: ambos tendem a explorar o meio onde vivem, ensaiar conexões e desconexões, experimentar devires. É nessa lúdica irreverência que tomam corpo seus territórios de existência - brincadeira, num caso, obra, no outro -, subjetividades em elaboração, indissociáveis do meio. Criança e artista seriam, portanto, os modos de subjetivação que mais se distanciam da situação reinante de torpor do sensível e nivelamento da percepção e que mais se aproximam da anomalia.

Entretanto, a realidade está longe disso: exatamente por sua anomalia, artistas e crianças interessam especialmente ao capitalismo renovado. Se o artista, como visto, é incontestavelmente atraente para a indústria da clonagem, na criança, o exercício da capacidade poética tende a ser inibido pela infantilização, produto das forças aliadas do familialismo, da pedagogização e do mercado que fazem dela um consumidor mirim.

Ora, crianças que vivem ou viveram na rua talvez sejam as que mais escapem à infantilização, pois sua própria condição as obriga a explorar e cartografar os meios por onde circulam, de modo a improvisar territórios de existência. São pequenas comunidades autogeridas, que se formam e se dissolvem na velocidade de seu nomadismo forçado pelos imprevisíveis remansos da vida urbana. Mas atenção, seria certamente ingênuo idealizar essas crianças: confinado à cloaca da cidade, o exercício desta sua potência não desemboca em nada além da sobrevivência, isto quando bem-sucedido, o que já é muito em face do destino de morte violenta e prematura que ameaça aquelas existências sem-valia.

É verdade que o equívoco mais recorrente em relação a essas crianças não é sua idealização, mas sua diabolização ou vitimização. Quando diabolizadas, o desejo é de eliminá-las do cenário, e o caso é de polícia ou de justiça; quando vitimizadas, o desejo é de salvá-las, e o caso fica então entre à psicologia, à pedagogia e à arte. É evidente a necessidade de serem criadas, para estas crianças, oportunidades de sair da marginalidade e, portanto, é incontestável o valor de iniciativas com esta pretensão, seja da psicologia, da pedagogia, da arte, ou de qualquer tipo de associação entre elas. O perigo é de, ao invés de reconhecerem o modo próprio de subjetivação daquelas crianças em sua positividade, para dele extrair uma potência em sua inserção, tais iniciativas as enxerguem como vítimas que deverão ser salvas através do modelo da criança infantilizada, que tentam projetar sobre elas. Quando isto prevalece, um efeito paradoxal pode resultar da generosidade que move esse tipo de prática: não encontrando ressonância, a força poética, especialmente viva naquelas existências, corre o risco de minguar. Neste caso, em vez de combatida, a inibição dessa força estará sendo reiterada, agora não mais pela exclusão social, mas pela domesticação, que pretende integrar essas crianças ao mundo dos clones infantis; no lugar de anômalos, lhes caberá então o destino de cidadãos normais, provavelmente com menos chances de "sucesso" - isto quando não caírem na categoria de anormais e em sua conseqüente patologização.

Como criar meios para favorecer a inserção dessas crianças sem que elas percam sua preciosa anomalia? O que a arte tem a ver com isto? Estas e outras perguntas envolvem tal complexidade, que a única coisa que se pode pretender é pensá-las o mais precisamente possível, e experimentar estratégias que as problematizem o mais fortemente que se conseguir.

A proposta de Tunga vai nesta direção: encontrar procedimentos que façam do encontro com aqueles garotos a ocasião, por mais fugaz e incerta, de driblar, na alma da criança que já viveu na rua, mas igualmente na alma do artista, a faceta perversa do sistema econômico vigente que tende a cercear sua potência criadora, excluindo um e clonando o outro. Para isso o artista terá que contar com a cumplicidade de uma sintonia efetiva com aquelas crianças. É na anomalia, comum aos dois, que ele irá encontrar esta cumplicidade; mais precisamente, na anomalia que busca afirmar-se enquanto tal sem ser clonada, nem mar- 
ginalizada. De fato, há provavelmente sintonia entre uma criança que já viveu na rua e está em luta contra sua marginalização, mas tentando através da arte não perder sua singularidade, e um artista que se associa ao sistema da arte que lhe oferece oportunidades de realização, mas não perde a força problematizadora de seu trabalho de criação, artista que resiste, portanto, à cafetinagem do sistema, sem cair no man's land da marginalidade - sem dúvida, o caso de Tunga. De todo modo, há provavelmente mais sintonia entre este tipo de criança e este tipo de artista do que entre uma criança que já viveu na rua e a maioria das crianças infantilizadas que vivem em família. Do mesmo modo, há provavelmente mais sintonia entre este tipo de artista e este tipo de criança, do que entre ele e artistas que se submetem sem crítica a tal cafetinagem, e até a desejam, chegando inclusive a conduzir a criação para tornar-se seu objeto (Gil, 1998); ou entre este tipo de artista e aqueles que se mantêm fora da jogada, remanescentes tardios de um romantismo supostamente heróico. Atualizar esta sintonia virtual entre anômalos, para criar um campo de forças que os sustente, que lhes permita resistir à cafetinagem de sua força criadora e que libere devires nos dois campos, ainda que infinitesimais, é o desafio que Tunga parece propor-se a enfrentar. O quanto isso será possível não dá para prever. Efeitos deste tipo dependem de uma trama complexa e sutil de fatores; não há como planejá-los; eles acontecem ou não.

Tunga apostará todas suas fichas na potência do ritmo na cultura baiana, que ele pretende convocar em sua instauração Salitre + Enxofre + Carvão. Este ritmo é uma importante força no processo de subjetivação dos baianos que, por sua exuberância, tornou-se de uns anos para cá a menina dos olhos da indústria fonográfica, a qual extrai daí matéria-prima para a fabricação de um de seus mais rentáveis produtos, seguindo a lógica do capitalismo contemporâneo anteriormente mencionada. Em sua ambigüidade imanente, esta estratégia tem ampliado espantosamente as oportunidades para os músicos baianos; mas, por outro lado, a tendência é o ritmo ser clonado e destituído de sua vitalidade, para ser devolvido ao mercado como um conjunto limitado de trejeitos estereotipados, mímica empobrecida que forma a identidade prêt-à-porter "estilo baiano": carcaça de um corpo reduzido a clichês de sexualidade, que perdeu o erotismo e a potência poética de sonhar mundos. A vertente perversa se completa com o consumo deste produto pelo próprio baiano de quem se extraiu a seiva para produzi-lo. O "baiano" que vem conquistando seu lugar no mercado multicultural do Brasil e do mundo globalizado tende a ser, em muitos casos, esta imitação servil de seu clone.

"Axé music" é o nome de um dos produtos desta vampirização do "axé" - palavra de origem iorubá que designa a energia sagrada dos orixás, poder vital presente em todos os seres e todas as coisas, força criadora, e que neste sentido mais amplo foi incorporada à língua brasileira. A indústria fonográfica, em seu vetor perverso, tem o cínico requinte de usar o próprio nome da força que parasitou - o axé -, para batizar seu clone estéril que ela fabrica e comercializa. Porém, o ritmo naquela cultura é um manancial tão rico que, apesar do sucesso desta maquinação sinistra, seu axé não se esgota, sua força de existencialização mantém-se viva, a criação não pára.

A instauração terá início com os garotos reunidos numa área lateral da exposição, como numa concentração de escola, formando um grupo compacto e fazendo uma certa algazarra. Com um aceno de Tunga, a arruaça se generalizará sob a forma de um bloco que desfilará arrastando e rolando os tambores pelo chão, armando uma verdadeira hecatombe musical. Aos poucos, cada um irá se desgarrando do grupo, sozinho ou em par, com a tarefa de encontrar seu lugar naquele espaço. Uma vez instalado, irá descobrir as substâncias e utensílios domésticos que Tunga colocou a seu dispor. ${ }^{8}$ Com curiosidade investigativa, deverá então improvisar um uso musical daqueles apetrechos, com a única ressalva de evitar qualquer referência conhecida.

Tunga fará do museu o espaço de um ritual, que oficiará a abertura da exposição, transformando o museu num híbrido de arte e terreiro. Ao pedir aos garotos que busquem um a um seu lugar naquele espaço, é o traçado de seus corpos que demarcará ritualmente os territórios, criando uma nova paisagem na geografia tanto do museu quanto de suas existências. Ao pedir em seguida, que uma vez instalados, pesquisem os utensílios de seu cotidiano e façam com eles um som desconhecido, também os objetos estarão adquirindo uma função ritualística. $\mathrm{O}$ tambor é o objeto emblemático por excelência do tráfico do ritmo efetuado pela indústria fonográfica, a qual o faz transitar de instrumento ritualístico e criador, para matriz de clonagem e sua mimese. Não por acaso, aqui é exatamente o tambor que será o agente do caminho de volta, ou mais precisamente do caminho de ida, agente da resistência. Com os tambores se arrastando e rolando pelo chão, produzindo aquela balbúrdia sonora e, depois, no encontro dos tambores com os utensílios domésticos transformados em instrumentos improvisados, gerando aquele som 
estranho, um quebra-quebra ou arrastão sonoros se anunciarão eventualmente na memória. Porém, na verdade, se algo estará se quebrando, por um breve momento, é o invisível jogo de cartas marcadas da relação entre o museu e seu fora, levando de roldão a marginalização daqueles meninos, a clonagem de seu ritmo e da força do artista. Por um breve momento, talvez se quebre a tendência de mimetizar o clone de si mesmo que uma cena como esta, de grande visibilidade e prestígio, poderia estar mobilizando no artista, como nos garotos; e, ao invés disso, se reative, no artista, a potência crítica da arte e, nos garotos, a potência do ritmo como agente de construção de território. Um quebra-quebra invisível, macumba para os novos tempos.

O caráter ritual das instaurações de Tunga situa-se no rastro do caminho aberto na arte por Lygia Clark, para quem o artista contemporâneo é o propositor de "um rito sem mito". De fato não haverá aqui nem rito, nem mito, estabelecidos a priori. O ritual será comandado pela realidade sensível daqueles garotos, convocada em sua alma e encarnada em seus gestos, na ginga refinada de seus corpos e em seu modo de explorar os objetos conhecidos naquele universo desconhecido, tateando o estranhamento que esta ambigüidade mobiliza. O mito se engendrará do próprio ritual, mapa imanente da singularidade daquelas vidas. É esta liberdade de cartografar, driblando a clonagem de suas cartografias, que estará se inscrevendo em sua alma, como um mito apropriado para o contemporâneo, na contracorrente da eternidade de mitos absolutizados do passado, mas também do valor genérico dos mitos descartáveis do presente.

Terminada a instauração, espera-se que o acontecimento não se pacifique e que sua memória permaneça vibrando durante todo o tempo da exposição, nos objetos que compõem a instalação: restos do ritual que se deu naquele recinto, como ficam restos de despachos na natureza ou em encruzilhadas das cidades, esperando que o recado chegue aos Orixás. Contaminada pelo meio onde se produziu desta vez, a obra de arte revela-se como despacho, portadora de um poder mágico de interferência energética no ambiente, para nele combater as forças reativas e liberar a criação. Interferência imperceptível, mas efetiva. E, como todo despacho, fica na obra gravada a memória desta experiência: a afirmação da força político-poética na prática artística e a afirmação da força do ritmo de criança não infantilizada na subjetividade daqueles meninos - memória de uma linha de desterritorialização que os arrastou ambos, o que só foi possível por se tratar de um encontro entre as forças da anomalia em cada um deles, e assim mesmo por um breve instante. Não dá para saber se esta memória estará reverberando naqueles objetos, se os Orixás a terão ouvido e abençoado, nem por quanto tempo permanecerá no ar depois que a instalação tiver sido desmontada.

"Não há ato de criação que não pegue a revés, ou não passe por uma linha liberada", escrevem Deleuze e Guattari (1997). Promover algo que se pareça "com uma atmosfera ambiente, onde só a vida pode engendrar-se" (Nietzsche apud Deleuze e Guattari, 1997:363), ainda que fugazmente, é o que Tunga deseja com seus despachos nos museus. E, mesmo assim, como ele próprio prudentemente adverte, "sabe-se lá o que vai acontecer...".

\section{NOTAS}

E-mail da autora: suelirolnik@uol.com.br

Conferência apresentada em The Deleuzian Age, Californian College of Arts and Crafts (São Francisco, 2000).

1. Distinção proposta por Canguilhem (s.d.:81-82), e retomada por Deleuze e Guattari (1997)

2. Antonio Mourão, conhecido por Tunga, que nasceu em Palmares-PE, em 1952, é um artista reconhecido não só no país, mas com trabalhos que circulam no cenário internacional. "Instauração" é o nome dado por Tunga para uma estratégia recorrente em seu trabalho, consiste em incorporar à obra pessoas estranhas ao mundo da arte, protagonistas de uma espécie de performance, seguindo um ritual com objetos e materiais sugeridos pelo artista; restos da performance compõem uma instalação que permanece exposta. O conjunto formado pela performance + processo + instalação "instaura" um mundo.

3. Já em Camera Incantate (Palazzo Reale, Milão, 1980), obra em que Tunga trabalha com vários tipos de luz, o artista incorpora a performance de dois albinos e dois negros, o claro e o escuro. O albino fica dizendo que veio fazer uma "instalação" elétrica e que esse negócio de arte não lhe interessa. Depois desta primeira experiência, virão instaurações que se repetirão em diversos contextos, diferenciando-se a cada vez, formando séries, como acontece com suas instalações. São elas: Xifópagas Capilares (três vezes, em 1985, e três vezes, em 1989); Sero te Amavi (três vezes, em 1992 e uma, em 1995); Caro Amigo (1996); Passeio de Vanguarda em Veneza ou Debaixo do meu Chapéu (abertura da Bienal de Veneza, 1995 e retorna incorporada à Inside Out, Upside Down, abertura da X Documenta, Kassel, 1997). As séries de instaurações são sempre intercaladas com séries de desenhos, esculturas, ou instalações sem performance. Além disso os vários tipos de séries se compõem entre si, resultando em outras tantas obras. Por exemplo: Xifópagas Capilares com a instalação Lagarte/Lizart/Lesarte (Congresso de Psicanálise, Rio de Janeiro,1985).

4. Com Espasmos Aspiratórios Ansiosos (AIS ou Anxious Inhaled Startles; Rio de Janeiro, MAM, 1996); Experiência de Física Sutil (An Experiment on Keen and Subtle Physics) ou Avant-Garde Walk in Soho (Nova York, 1996), que retorna com outro nome em 1996 e novamente em 1997, incorporada à Inside Out, Upside Down.

5. É o caso das instaurações: Cem Terra, São Paulo, 1997, que volta no Reina Sofia, Madrid, 2001; Tereza, entrega do prêmio Johnny Walker, Museu de Belas Artes, Rio de Janeiro, 1998, que retorna no mesmo ano na galeria Cristopher Grime, Los Angeles, em 1999, no Centro Cultural Ricoleta, Buenos Aires, e em 2000, na Bienal da Coréia e na Bienal de Lyon; e, por último, a proposta para The Quiet in the Land II, Salvador, 2000, aqui privilegiada.

6. A esse respeito, são significativas as anedotas em torno de Tereza. Quando a instauração foi feita pela primeira vez, com figurantes recrutados no Rio de Janeiro, muitos deles já haviam passado por registro policial, talvez a maioria deles fosse composta de ex-presidiários. Quando Tunga lhes ensinou como fazer uma 
tereza, foi motivo de gargalhada geral. Na terceira vez que a instauração foi feita, em Buenos Aires, os protagonistas foram sem-teto recrutados nas ruas por um grupo de jovens anarquo-surrealistas. A notícia de uma vaga de emprego, tão rara para aquela população, espalhou-se muito rapidamente pela cidade, provocando uma fila enorme de candidatos no dia da seleção.

7. A Quietude da Terra II é um projeto criado por France Morin (fundadora da revista de arte canadense Parachute e ex-curadora do New Museum of Contemporary Art de Nova York). A curadora convidou 17 artistas contemporâneos de diferentes países, para que cada um desenvolvesse, durante um mês e meio, um projeto com grupos de crianças que já viveram nas ruas de Salvador. O conjunto dos trabalhos teve sete meses de duração, entre 1999 e 2000. Uma exposição com as obras resultantes dos 17 projetos foi organizada no MAM da Bahia, em julho de 2000, acompanhada de um livro/catálogo bilíngüe. O acesso às crianças se deu através de uma parceria com o Projeto Axé, instituição baiana que há vários anos vem desenvolvendo um trabalho pedagógico e artístico com meninos que vivem na rua.

8. Entre os objetos, Tunga privilegia os de folha de flandres, utensílios artesanais que imitam aqueles de alumínio fabricados industrialmente e recriam, à sua maneira no dia-a-dia das casas mais humildes, um certo cenário das casas abastadas - funis, raladores, assadeiras, batedores de clara, pás de pegar farinha ou açúcar em barracas de feira, lamparinas, fiofós, agulhas e fios. Acrescentará, ainda, ob jetos de algodão - rolos e cotonetes -, mas também limpadores de copo e garrafa, coadores de café, etc. E mais outros tantos apetrechos: luvas de borracha de operário, rabinhos de coelho, etc. Entre as substâncias, ceras, farinhas e ingredientes do gênero, e três bacias contendo salitre, enxofre e carvão, respectivamente.

\section{REFERÊNCIAS BIBLIOGRÁFICAS}

CANGUILHEM, G. Le normal et le Pathologiqe. s.l., PUF, s.d.

DELEUZE, G. e GUATTARI, F. "Percepto, afecto e conceito". O que é a filosofia? São Paulo, Ed. 34, 1992 (Tradução Bento Prado Jr. e Alberto Alonso Muñoz).

. "1730 - Devir-intenso, devir-animal, devir-imperceptível...”. Mil Platôs. São Paulo, Ed. 34, v.4, 1997 (Tradução Suely Rolnik).

GIL, J. "A confusão como conceito". Os anos 80. Lisboa, Culturgest, 1998.

ROLNIK, S. "Toxicômanos de identidade". Conferência na X Documenta. Kassel, 1997 